\title{
The 50th Anniversary of the M. M. Shemyakin \& Yu. A. Ovchinnikov Institute of Bioorganic Chemistry of the Russian Academy of Sciences
}

\author{
By Academician V.T. Ivanov, Director of the Institute
}

Under the February 20,1959, Resolution of the Presidium of the USSR Academy of Sciences, the Institute for Chemistry of Natural Products was founded within the Academy's Chemical Sciences Division. The institution would go on to play an important part in the development of Russian physical and chemical biology. The founding of the Institute was brought about by the rapid developments in the chemistry of bioactive compounds, the natural products among them, and reflected the growing importance of this field in understanding the mechanisms of biological processes and in development of new medicinal preparations.

\section{$\mathrm{T}$} he leader of the natonal antibiotics chemistry, academician Mikhail Mikhailovich Shemyakin, was appointed head of the Institute, and he managed to lure the best specialists working in different fields: in the chemistry of carbohydrates, V.N. Orekhovitch and V.M. Stepanov; in the chemistry of antibiotics, future academicians A.S. Khokhlov and M.N. Kolosov, as well as future corresponding member V.K. Antonov; and in the chemistry of lipids, future corresponding member L.D. Bergelson. Recent graduates from higher educational institutions also joined the team and later became members of the USSR Academy of Sciences; they retained, to a significant degree, the scientific identity of the Institute (Yu.A. Ovchinnikov, V.F. Bystrov,
E.V. Grishin, V.T. Ivanov, A.I. Miroshnikov and E.D. Sverdlov).

After a short period of time, the Institute became a top scientific establishment in its field in the country, actively interacting with the international community (multiple publications in foreign magazines and broad participation in international symposia).

In the case of depsipeptide antibiotics, the molecular mechanism of the induced cationic permeability of biological and artificial membranes was decoded; the causes of the unique in several cases ionic selectivity were revealed, and the synthesis of a series of new high-performance membrane-active complexons was conducted. A new class of non-glyceride neutral lipids present in a broad variety of different organisms (plants, animals and micro- organisms) was discovered, and their role in the biomembranes' functioning was demonstrated. New methods of carbohydrate, steroid and lipid synthesis, as well as selective modification of the nucleic acids, were extensively developed. For the first time, the full synthesis of tetracycline was performed, an antibiotic of practical importance and with a most complicated structure. In a collaborative effort by several laboratories, a new comprehensive approach for establishing the spatial structure of peptides in solution based on the coordinated application of a set of spectral and computational methods was developed. The efficiency of this approach was proved through numerous examples of natural and synthetic peptides, with membrane active antibiotics and toxins among them. A new, so called topochemical approach was developed to design and synthesize of biologically active peptides - hormones, antibiotics, toxins, substrates and enzyme inhibitors.

In 1970, after M.M. Shemyakin's death, academician Yu.A. Ovchinnikov became the head of the Institute and the vice president of the USSR Academy of Sciences from 1974.

The 70 s and the 80 s were years of rapid development in physico-chemical biology in the USSR and of an intensive effort to narrow the gap in the level of research from the best laboratories in the world. The Government passed a 


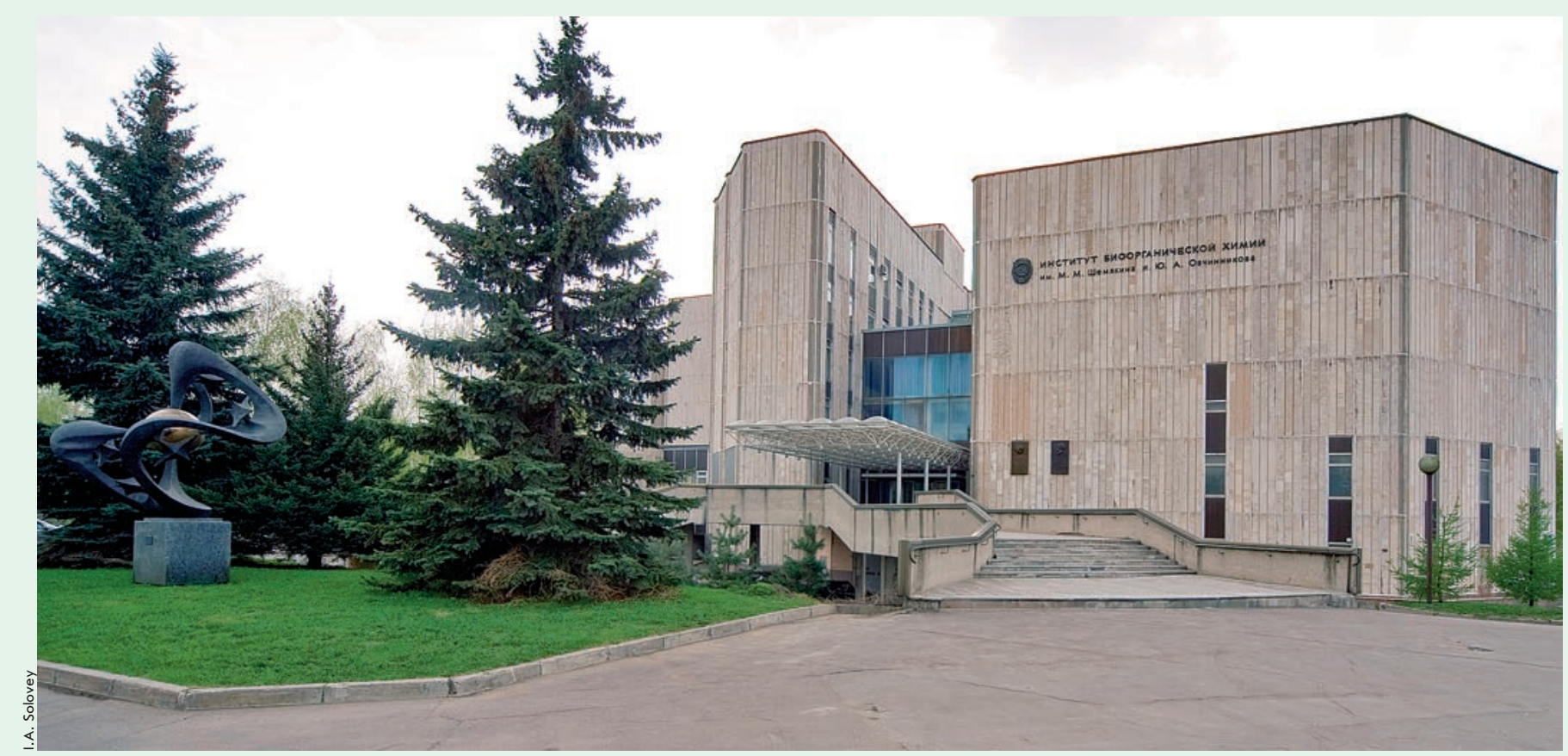

decision on comprehensive support for this scientific field, whose progress essentially determined progress in the spheres of medicine, agriculture, environmental protection and biosecurity. The Institute was appointed as a leading institution responsible for implementation of the corresponding government decrees. Its main area of activity became investigation of biological problems with the help of the methods of organic chemistry. That trend led to change of name in 1973 to the Institute of Bioorganic Chemistry and, correspondingly, the proportion of biological research in it essentially increased. Institutes under analogous names and similar scientific tasks were founded in Novosibirsk, Vladivostok, Kiev, Minsk, and Tashkent. Beginning from 1975, the Bioorganic Chemistry Journal was started, based in the Institute and issued by the publishers Nauka. In the same year, a chair of bioorganic chemistry was founded in the Biological Faculty of Moscow State University and Yu.A. Ovchinnikov became its first Professor. In 1974, construction of a new building for the Institute was started in the south west of Moscow, and the building became operational in 1984. Scientists were provided with a superb set of build- ings meeting their needs in specialized facilities and engineering equipment; this equipment has continued to efficiently operate to this day.

As the Institute progressed, the focus of its interest shifted from low molecular bioregulators to the major biopolymers of the cell, primarily to proteins and nucleic acids. In 1972, in a collaborative effort by two Institutes the Institute of Bioorganic Chemistry and the Institute of Molecular Biology - the full primary structure was established for the porcine cardiac muscle cytoplasmatic aspartate aminontansferase, the first protein sequenced in our country.. It was a significant achievement for that time. During the following years, the number of sequenced proteins grew exponentially. The groundbreaking work on the structure of integral membrane proteins - bacteriorhodopsin (1978) and bovine rhodopsin (1982) deserves special attention. The task was completed under conditions of strong competition with the best foreign laboratories, and this story clearly demonstrated the remarkable progress of biomolecular science in the USSR at that time.

From the early 80 s, the Institute became one of the top biotechnological centers in the country. Researchers at the Institute had been extensively developing methods for chemical-enzymatic synthesis of nucleic acids. The latter was further applied as an important component of genetic engineering technologies for the production of recombinant proteins. The interferon a 2 strain producer obtained in the Institute served as a basis for the following industrial production of this important medicinal preparation. Beginning from 1985, and after 1988, this time without Yu.A. Ovchinnikov, who passed away untimely, the Institute became the head organization in the structure of the Inter-Industry Scientific and Technological Biogen complex, which united dozens of scientific and manufacturing biotechnological centers in the country. Beginning from 1992, the Institute took the lead in the Novel Methods in Bioengineering national program.

A decision was reached on establishing the Pushchino Branch of the Institute of Bioorganioc Chemistry in 1979, and in 1988 construction work was completed. Facilities for growing plants under controlled conditions and an excellent animal house, as well as pharmacological laboratories for conducting preclinical trials of medicinal preparations, were now available. These facilities significantly enhanced the potential 
of the Institute for carrying out work in the sphere of plant biotechnology and for creating new drugs.

Today, the Institute of Bioorganic Chemistry is the largest among the Biology Sciences Branch Institutions of the RAS. The Institute includes 40 independent laboratories and groups conducting research in a wide range of directions. The scientific council of the Institute has approved the following main directions in its work:

- Isolation and structural analysis of new biomolecules. Studies of their structure-functional relations and the mechanisms of action;

- Biocatalysis;

- Structure and function of proteins and peptides;

- Structure and function of nucleic acids.

- Molecular mechanisms of genetic processes;

- Mechanisms of biomolecular recognition and signal transduction in biological systems;

- Molecular and cell immunology;

- Biomedical research;

- Fundamental and applied aspects of biotechnology;

- New reagents, materials and equipment.

In each of the above-mentioned directions, new original results have been obtained and presented in hundreds of publications, patents and reports. Among the achievements of recent years worth mentioning are: discovery of new fluorescent protein families in marine organisms (coral polyps and ratchets), their structure identification and development of genetically coded markers for the visualization of cell processes on their basis. Protein components have been isolated and identified from animal poisons. Several of them display unique selectivity of membrane action and membrane receptor binding, in particular, on pain receptors. These proteins might serve as an instrument for the study of signal transduction mechanisms in biological systems and for the development of new medicinal preparations. New approaches to comparing the full genomes of closely related organisms have been developed.. This method has been used for unraveling genetic differences between humans and chimpanzees, the differences that reflect the integration of endogenous retroviruses. A new direction has been developed in peptide research called peptidomics. Total screening of several biological objects has been carried out in order to detect the presence of endogenous peptides, and it has been shown that any kind of protein can serve as a source of biologically active peptides, including those with a well studied individual function (for example, hemoglobin).

Development of new pharmaceuticals ("Deltaran", "Likopid") registered with the State Register of Medical Products of the Russian Federation, as well as manufacturing of the most important recombinant protein preparations, such as human insulin and human growth hormones, is worth mentioning among work of immediate practical value. At present, our Institute supplies about $15 \%$ of the Moscow Health Care system's needs in insulin.

A more comprehensive description of the achievements of the Institute would go far beyond the size of this brief survey. However, even the examples provided here speak to the great potential of the working team and the Institute's perspectives. The work of researchers of the Institute has received two Lenin Prizes, ten State Prizes in the field of science and engineering, five Government of the
Russian Federation Prizes in the field of science and engineering, the USSR Academy of Sciences and RAS Prizes named after A.N. Bach, A.O. Kovalesky, Yu.A. Ovchinnikov, and M.M. Shemyakin.

A very significant aspect of the Institute's work is its participation in the teaching and training process in the sphere of bioorganic chemistry and biotechnology. Regular acceptance of talented young people has allowed us to remain scientifically competitive during the period of mass migration of scientists to foreign laboratories. A Scientific Educational center collaborating with several high educational institutions in Moscow, Sankt Petersburg, and Pushchino was founded in the Institute. Leading scientists lecture on specialized topics, and more than 100 undergraduate students on a regular basis join the Institute's laboratories preparing bachelor and master thesis and participating in scientific publications. A series of practical classes have been organized, and corresponding exams and tests have been administered. As a result, the Institute has an opportunity to enroll several graduates annually into post graduate courses and then hire them to work for the Institute. That workforce has a full-scale education and is able to tackle complex scientific problems.

As a whole, the Institute of Bioorganic Chemistry may be considered today as one of the key constituent parts of the system of Institutes in the Biological Sciences Branch of the RAS. The Institute's personnel and its capabilities are ready to fulfill scientific tasks of any degree of complexity. We greatly appreciate the understanding of the necessity of our work by our fellow countrymen and the support of the government. 